\title{
The hygiene hypothesis: promises and pitfalls
}

The popular hygiene hypothesis for allergy and asthma has been riding on a swell of provocative evidence over the past decade. Broadly stated, naturally occurring infections and microbial exposures might confer protection against the development of asthma and allergic and autoimmune diseases. Common microbial exposures-viral and bacterial infections, gastrointestinal tract colonization, and exposure to certain microbial components such as bacterial endotoxin-are potent inducers of immune memory, Th1 immune responses, and regulatory immune responses. They are implicated in this scheme. Murine atopic asthma models have consistently revealed that microbial infections (e.g., BCG, M. pneumoniae), killed bacterial organisms (e.g., heat-killed listeria), bacterial immune stimulatory components (e.g., bacterial endotoxin or CPG motif DNA), or the Th1-type cytokines they induce (e.g., IFN-g, IL-12) can all prevent induction of the allergic asthma phenotype (reviewed in [1]). The relevance of this concept in humans has been supported by observations from natural history studies and detailed population studies which have begun to explore the causal relationships between these microbial exposures and the subsequent development of the immune system, allergy and asthma.

I would like to commend and thank Drs. Gore, Custovic, van Schayck, and Knottnerus for a lively and thoughtful debate on this hygiene hypothesis [2-5]. I join them in that much of the current epidemiological data are not strong enough to infer causation. Quantity and lay appeal of studies does not equal quality, and ultimately quality will be needed to prove it. However, randomized controlled trials of high quality, although ideal, are not always feasible in proving causation. This challenge in not unique to the hygiene hypothesis, and is common in the study of disease causation. Specific epidemiological criteria have been established that can prove a strong causal relation, and can be used to weigh the evidence for the hygiene hypothesis [6]. The strongest evidence is usually developed from prospective cohort studies where the development from cause to subsequent effect can be examined carefully. Indeed, randomized controlled trials are an optimized variant of longitudinal prospective studies.

We have found it helpful to study bacterial endotoxin as a prototypical microbial adjuvant and exposure [1]. Briefly, endotoxin is a lipopolysaccharide that comprises most of the outer cell wall of all gram-negative bacteria. It is a ubiquitous and potent inducer of immune memory, Th1 immune development, and also of regulatory immune mechanisms that keeps immune responses appropriately contained and controlled. Th1 immune development is believed to/mitigate the development of allergic diseases and asthma through a number of pathways. The classic paradigm is that Th1 down-modulates Th2 development and atopy. Th1 immune responses also induce multiple anti-viral mechanisms that keep respiratory viruses from proliferating in the respiratory epithelium and spreading down the airways. Th1 immune responses during airways injury and inflammation also inhibit aberrant repair processes that underlie tissue changes in asthma. For example, IFN-g inhibits mucous gland and smooth muscle hyperplasia, fibrotic repair processes, and mast cell activation, through direct and indirect mechanisms.

Endotoxin is therefore considered to be a prototypical pathogen-associated molecular pattern (PAMP), which are fundamental components of microbes that the immune system relies heavily on to recognize them. From this scientific basis, along with clinical investigations of endotoxin exposure, primarily in occupational settings, we have envisaged endotoxin exposure to be both harmful and helpful-harmful in that, at high exposure levels, some people will develop an occupational form of asthma (i.e., byssinosis). Also, if asthma or allergic diseases are ongoing, then endotoxin-an adjuvant-is like gas on a flame and will increase 
inflammation and disease severity. On the other side, endotoxin could help to promote healthful immune responses to microbial pathogens and other ubiquitous environmental exposures such as allergens. Most importantly, the determinants for harmful or healthful outcomes include: timing and dosage of exposure, environmental co-factors, and genetics. These have been the focus of careful investigations in recent years. To summarize, current evidence suggests that early timing, moderate exposure levels, environmental co-exposures such as other PAMPs and allergens, and genetic polymorphisms that influence response to exposure, are all important determinants of healthful or harmful outcomes due to endotoxin exposure.

In support of these relationships is the compelling work of European investigators of several farm/non-farm communities, who have reported the following associations between greater endotoxin exposure and asthma and allergy outcomes in school-age children:

1. Farm children are exposed to more endotoxin (as measured in house dust, barn dust, and mattress dust) $[7,8]$;

2. Greater endotoxin exposure is associated with less allergen sensitization, hay fever symptoms, and atopic asthma, in a dose-dependent manner [8];

3. The blood cells of farmer's children expressed higher amounts of CD14 and Toll - like receptor 2, which are innate immune receptors for microbial compounds that include endotoxin [9];

4. Recollection of early life exposures to farm barns and unpasteurized milk had the strongest associations with low asthma and allergy prevalences [10]; and

5. High levels of endotoxin exposure were associated with an increased prevalence of non-atopic wheeze [8].

Therefore, natural endotoxin exposure may promote early Th1-type immune development, thereby preventing the development of allergen sensitization, allergic airways conditions, and asthma. As well, high levels of endotoxin exposure may bring out endotoxin-sensitive asthma in the vulnerable, similar to occupational forms of endotoxic asthma.

Could a similar phenomenon be true for pet animal exposures in typical metropolitan homes? Sticking with well-performed, longitudinal studies, two recent birth cohort studies in US metropolitan communities have found less subsequent asthma in children raised with pet dogs [11], and less subsequent allergen sensitization with increasing numbers of pet cats and/or dogs in early life [12]. In a third birth cohort study, dog ownership in par- ticular was associated with less atopic dermatitis, less food allergy, and less allergen sensitization at 1 year of age [13]. Interestingly, dog ownership was also associated with increased IL-10 production from peripheral blood cells (a biomarker of immune regulatory responses). Furthermore, the effect of dog ownership on atopic dermatitis was strongest for those children with a high-responder polymorphism in their CD14 promoter region (which is a receptor/enhancer binding protein for endotoxin). Although the mechanism(s) for this potential protective influence are unclear, one possibility is that greater microbial (e.g., endotoxin and other PAMPs) exposure occurs with animal contact and/or animal/pet-keeping in the home. Recent studies have reported that indoor pets are a major factor associated with higher indoor endotoxin levels in metropolitan homes [1,14].

In closing, as the authors have espoused, a word of caution when seeking to extrapolate these early investigative clues into action. The hygiene hypothesis argument for the prevention of allergy, asthma and autoimmune diseases has not been developed strongly enough to provide any course of action for either prevention or therapy. The current evidence, however, is intriguing and can well substantiate an investigative blueprint from which essential studies can be targeted and developed, and causation between microbial exposures and subsequent allergy, asthma, and autoimmunity can be tested. In the meantime, what is well understood about interventions that optimize human health should prevail.

\section{References}

[1] Liu AH. Endotoxin exposure in allergy and asthma: reconciling a paradox. J Allergy Clin Immunol 2002;109(3):37992.

[2] Gore C, Custovic A. Protective parasites and medicinal microbes? The case for the hygiene hypothesis. Prim Care Respir J 2004;13(2):68-75.

[3] van Schayck CP, Knottnerus JA. No clinical evidence base to support the hygiene hypothesis. Prim Care Respir J 2004;13(2):76-9.

[4] Gore C, Custovic A. Response to 'No clinical evidence base to support the hygiene hypothesis' by CP van Schayck and JA Knottnerus. Prim Care Respir J 2004;13(2):80-2.

[5] van Schayck CP. Response to 'Protective parasites and medicinal microbes? The case for the hygiene hypothesis' by C Gore and A Custovic. Prim Care Respir J 2004;13(2):83.

[6] Liu AH, Murphy JR. Hygiene hypothesis: fact or fiction? J Allergy Clin Immunol 2003;111(3):471-8.

[7] Gereda JE, Leung DYM, Liu AH. House-dust endotoxin is higher in rural homes in developing countries and farm homes, where asthma is less prevalent. JAMA 2000;284(13):1652-3. 
[8] Braun-Fahrlander C, Riedler J, Herz U, Eder W, Waser M, Grize L, et al. Environmental exposure to endotoxin and its relation to asthma in school-age children. $\mathrm{N}$ Engl J Med 2002;347(12):869-77.

[9] Lauener RP, Birchler T, Adamski J, Braun-Fahrlander C, Bufe A, Herz U, et al. Expression of CD14 and Toll-like receptor 2 in farmers' and non-farmers' children. Lancet 2002;360(9331):465-6.

[10] Riedler J, Braun-Fahrlander C, Eder W, Schreuer M, Waser $M$, Malsch $S$, et al. Exposure to farming in early life and development of asthma and allergy: a cross-sectional survey. Lancet 2001;358:1129-33.

[11] Remes ST, Castro-Rodriguez JA, Holberg CJ, Martinez FD, Wright AL. Dog exposure in infancy decreases the subsequent risk of frequent wheeze but not of atopy. J Allergy Clin Immunol 2001;108:509-15.

[12] Ownby DR, Johnson CC, Peterson EL. Exposure to dogs and cats in the first year of life and risk of allergic sensitization at 6 to 7 years of age. JAMA 2002;288(8):963-72.
[13] Gern JE, Reardon CL, Hoffjan S, Nicolae D, Li Z, Roberg KA, et al. Effects of dog ownership and genotype on immune development and atopy in infancy. J Allergy Clin Immunol 2004;113:307-14.

[14] Gereda JE, Klinnert MD, Price MR, Leung DYM, Liu AH. Metropolitan home living conditions associated with indoor endotoxin levels. J Allergy Clin Immunol 2001;107:790-6.

Andrew H. Liu

Division of Allergy \& Immunology

Department of Pediatrics

National Jewish Medical and Research Center University of Colorado Health Sciences Center

1400 Jackson Street (K1023)

Denver, CO 80206, USA

Tel.: +1-303-398-1143; fax: +1-303-398-1225

E-mail address: liua@njc.org (A.H. Liu)

Available online at www.sciencedirect.com

science 0 Direct

Available online at http://www.thepcrj.com

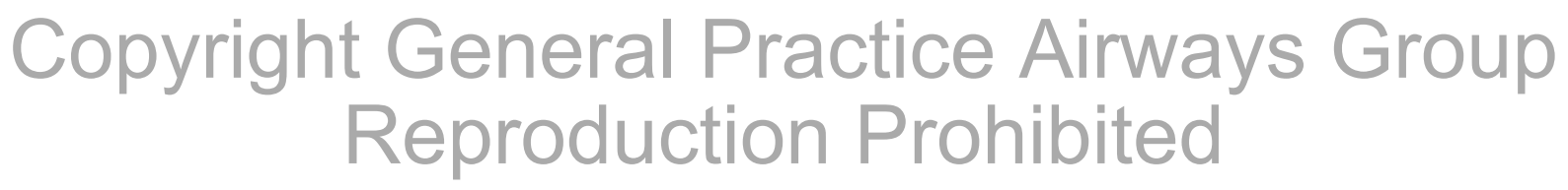

